\title{
Urban Circular Economy in China: A Review Based on Chinese Literature Studies
}

\author{
Fang Su, ${ }^{1}$ Jiangbo Chang, ${ }^{1} \mathrm{Xi} \mathrm{Li},{ }^{1}$ Dan $\mathrm{Zhou}^{2}$ and Bing Xue $\mathbb{D}^{2,3}$ \\ ${ }^{1}$ School of Economics and Management, Shaanxi University of Science \& Technology, Xi'an 710021, China \\ ${ }^{2}$ Jiangxi Key Laboratory of Mining \& Metallurgy Environmental Pollution Control, Jiangxi University of Science and Technology, \\ Ganzhou 341000, China \\ ${ }^{3}$ Key Lab of Pollution Ecology \& Environmental Engineering, Institute of Applied Ecology, Chinese Academy of Sciences, \\ Shenyang 110016, China
}

Correspondence should be addressed to Bing Xue; xuebing@iae.ac.cn

Received 28 August 2020; Revised 30 September 2020; Accepted 26 February 2021; Published 4 March 2021

Academic Editor: Jianhong (Cecilia) Xia

Copyright $(2021$ Fang Su et al. This is an open access article distributed under the Creative Commons Attribution License, which permits unrestricted use, distribution, and reproduction in any medium, provided the original work is properly cited.

Circular economy is a critical approach to realize the coordinated development of society, economy, and ecological environment. Given the fact that urban is a complex system in which human beings integrate material, energy, information, and natural environment and interact and influence each other, reviewing the urban circular economy research and development could benefit for having a better and comprehensive understanding on urban complexity. Mainly based on the Chinese literature studies from 1999 to 2020, this study aims to present an in-depth analysis of the research themes, policy systems, and index system of China's urban-scale circular economy, discuss the changes and evolution trends of themes, levels, and perspectives in time series, sort out the policy systems at both the national and local levels, and analyze the design principles and application fields of indicators. Finally, we propose that future development of an urban circular economy should be built based on modern techniques, technologies, and models. The construction of development mechanism on the circular economy should be framed as "government-led, market-driven, legal norms, policy support, technological support, and public participation" and inject concepts such as "Internet +," "sharing economy," "Internet of Things," and "artificial intelligence."

\section{Introduction}

Since the 2000s, there has been an upsurge of research on the circular economy in the world, and the urban scale is considered as a critical frontier to develop a circular economy $[1,2]$. Given the fact that urban is a complex system in which human beings integrate material, energy, information, and natural environment and interact with each other $[3,4]$, the unity of opposites between human beings and the natural environment can be well reflected within the complex structure of urban [4]; therefore, the outcomes from urban circular economy research and practice could offer comprehensive insights and interdisciplinary thoughts on urban complexity. Investigating the urban circular economy can not only contribute to integrate different sectors such as business, public, and nongovernmental organizations but also benefit for long-term sustainability for both local and national levels.
Due to the various differences in the natural environment, economic developmental stages, and social and cultural background, there are significant differences in understanding and practice of circular economy among different countries and regions. Taking into account the circular economy, scholars have explored its context and concept from many aspects, for example, the definitions, processes, principles, influences, characteristics, and globalization $[5,6]$. In terms of the practice perspective, the development mode, policy system, development obstacles, countermeasures, and suggestions of the circular economy have been studied mainly from the aspects of elements, materials, enterprises, parks, regions, and society $[7,8]$, and the research fields mainly focus on material recycling, sustainable consumption, waste management, cleaner production, and resource efficiency $[9,10]$. 
China is being one of the global pioneers to develop urban circular economy [6-9], and many Chinese literature studies emerged, but they are rarely understood well by the world due to language barriers. Therefore, a review work of China's urban-scale circular economy could not only provide theoretical support and countermeasures for China's urban circular economy development but also could enrich and develop international circular economy practice and provide a reference for other countries. This paper aims to systematically sort out the existing academic achievements of China's urban-scale circular economy, explore the change characteristics and evolution trend of research themes, research levels, and research perspectives in time series, sort out the policy system and practice at national and local levels, and define the design principles and application fields of indicator methods.

\section{Methods and Data Sources}

The main literature and data source are mainly from CNKI (China National Knowledge Infrastructure) database, which is a key national research and information publishing institution in China, as well as the largest knowledge dissemination and digital platform in China. We applied a random searching method by using the CNKI search tool with the theme of the Chinese term "circular economy" plus "urban" with the time limitation until August 20, 2020, and then, 7369 Chinese literature studies have been obtained, including 3847 periodicals and journal papers, 2788 dissertations, 512 conferences, and 222 newspapers. With the help of the quantitative visualization analysis tool within the CNKI database, the characteristics and evolution trend of research themes, levels, and perspectives in the early, middle, and current stages are automatically identified. We also built a database about the official circular economy documents including policies, laws, and regulations from national-level agencies, as well as the local master plans and regulations from local governments and agencies, and finally, a total of 124 documents are selected out for conducting further analysis on the urban circular economy in China.

\section{Research Themes of Urban Circular Economy}

3.1. Concept and Characteristics. Circular economy is generally considered as a normative concept, aiming to achieve a more sustainable future and solve the environment without giving up economic prosperity [11-13], and various definitions have been given from different perspectives, such as economic form, comprehensive utilization of resources, environmental protection, or technological paradigm $[14,15]$. Urban is a kind of the center of human production and life and plays an essential role in economic and social development [16], which contains a series of human-natural elements, such as material, energy, information, environment, culture, economy, and institutions, and these elements will interact and influence each other [4]. With the acceleration of urbanization, the populations, energy consumption, and waste discharge from the urban are increasing rapidly. At the same time, the problems caused by environmental pollution, water shortage, and traffic congestion are also becoming increasingly severe, which has an impact on the development of cities, countries, and even the world [17]. Generally, compared with the "closing circle" advocated by the circular economy, urban circular economy pays more attention to the development, systematisms, and process [18], that is, the efficient recycling utilization, process improvement, and reorganization of the material, energy, and information in the urban system; therefore, the urban circular economy is usually recognized as a complex and open coupled system, and exploring the urban's circular economy has practical significance to achieve the coordinated development of society, economy, and ecological environment for urban. In addition to self-organizing operation, according to its laws, various elements and subsystems in the system also carry out mutual influence, interaction, and coupling of other organizations and organizations in a more extensive scope [19]. Based on the unique regional space of urban, researchers have studied on urban mineral, zero-waste city, cleaner production, urban garbage, eco-industrial park, sustainable urban development, urban transformation, green consumption, development mode, indicator system, development evaluation, and other themes from different perspectives of elements, materials, enterprises, parks, regions, cities, and society.

3.2. Topic Evolution. With the circular economy development as well as the changing of the institutional environment, the research theme, scale, and perspective of the urban circular economy also changed which could be categorized into 3 main stages (Figure 1).

In the early stage (before 2008), Chinese scholars' research on urban circular economy mostly focused on strategic planning and development models, the scale of enterprises, parks, and cities, and the exploration of production links. At the enterprise scale, scholars mostly choose typical enterprises and large enterprises and conduct ecological industrial pilot projects of individual enterprises through ecological product design and clean production, to reduce the use of materials and energy in products and services and to minimize pollutant emissions [20, 21]. At the industrial park's scale, scholars mainly start from practice to explore the planning and construction, development model, development strategy, and problems and countermeasures of the eco-industrial park [22]. From the perspective of production, scholars mainly explored the processes and technologies, standards, indicator systems, audits and evaluations, and legal systems of cleaner production [23, 24]. Through the accumulation of theory and practice, scholars have explored some typical development models of the circular economy, such as the mode of enterprise circular economy in Lubei of Shandong Province [25], Guigang mode driven by a sugar industrial park in Guangxi [26], and Guiyang mode with "one goal, two links, three core systems, and eight circular systems" as a strategic framework [27].

In the middle stage (2009-2016), Chinese scholars' research mostly started from the scale of urban, region, and society focused on efficiency evaluation, obstacle 


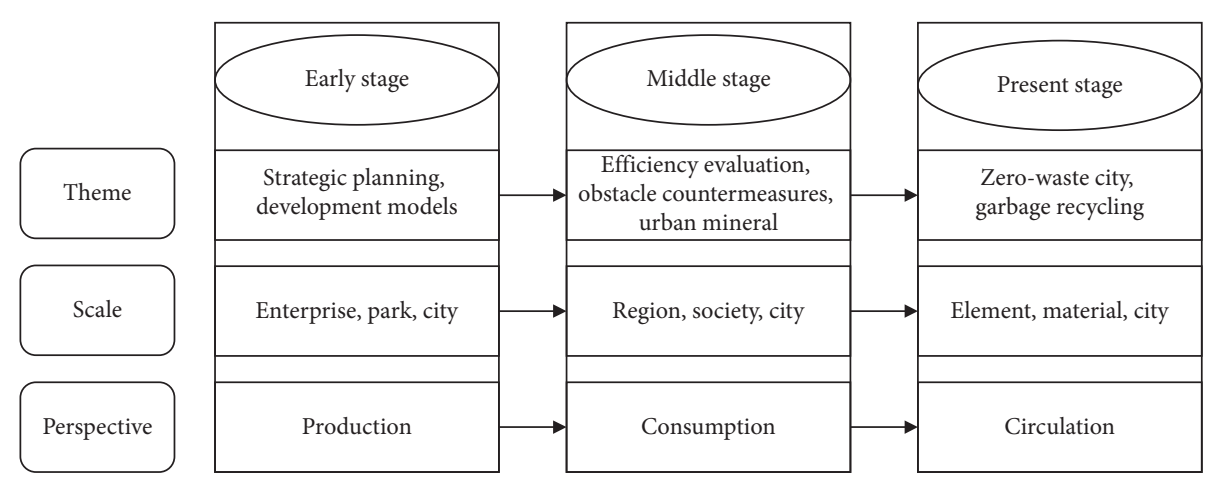

FIGURE 1: The theme evolution of the urban circular economy.

countermeasures, and urban minerals and focused on the exploration of consumption links. At this stage, from the perspective of urban scale, scholars have studied the concept, significance, problems, and countermeasures of urban minerals $[28,29]$. There are two main branches in the study of urban circular economy from the regional scale. The first one is to divide the urban into several regions which are mostly found in megacities such as Shanghai and Beijing [30], and another one is to explore the urban as a part of the region such as Wuhan city cluster, Changsha-ZhuzhouXiangtan city group, and Yangtze River Delta city group [31]. Society is a complex giant system involving resources, environment, economy, politics, culture, and many other aspects, which runs through all aspects of production, life, circulation, and consumption. The society scale of circular economy research mainly puts forward to build a resourcesaving and environment-friendly "two-oriented society." It defines the construction and evaluation of the two-oriented society in the city $[32,33]$.

At the present stage (from 2017 to now), scholars mostly discuss the zero-waste city, garbage recycling, and other aspects from the scale of elements, materials, and urban and focus on the circulation link. At the element scale, scholars have explored the urban-scale circular economy from the aspects of land, water, and energy, focusing on the evaluation of element utilization, influencing factors, and spatial and temporal changes $[34,35]$. According to the recycling of water resources, the construction plan of a sponge city is put forward in China [36]. At the material scale, scholars mainly focus on resources, products, waste, and other specific substances [37]. For example, Zhong studied the impact of gaseous pollutants and particulate matters released from crop straw incineration on regional urban air quality [38]. Centering on the resource utilization of solid waste, China has also put forward the construction plan of "zero-waste city" [39]. Discussing the circulation links of the urban-scale circular economy, on the one hand, it includes the circulation of elements, which pays attention to the recycling of components. On the other hand, it consists of the circulation of materials, emphasizing the development of green logistics, namely, green storage, green packaging, green processing, and green transportation [40].

In conclusion, from the perspective of the whole time series, the exploration of urban circular economy has always been the focus of research activities and contents. In addition to the systematic investigation of urban level, scholars' research scale has experienced the changes of median, macro, and micro, and the research perspective shows the laws of production, consumption, and circulation, which can be seen from these laws that people's research on urban-scale circular economy has become more and more specialized and complicated.

\section{Policy Systems Analysis}

Since 2000, China took the circular economy and the construction of Ecological Industrial Park as an important measure for addressing industrialization and realizing urban sustainable development, followed by quite a few practical and empirical studies in this field, and a series of policies have been issued at the national and local levels. In this section, the policy systems at the national level such as urban minerals, sustainable development of resource-based cities, sponge cities, waste-free cities, and ecological cities are presented, and some typical cases from Shanghai, Beijing, and Jiangsu Province are also introduced.

4.1. National Level. Along with the development process of the urban circular economy, the guidinig policies at the national level mainly include the following several key parts: (1) Urban mineral: China's national development and Reform Commission issued the "Notice on Carrying out the Construction of Urban Minerals Demonstration Bases" in 2010, which formally put forward the independent concept of "urban mining" for the first time [41]. "Urban mining" is an image metaphor for the large-scale development of waste resource recycling, which includes not only materials but also energy, such as heat generated in the smelting process $[42,43]$. (2) Resource-based city development: resourcebased city is a city that relies on the development and processing of natural resources for economic development [44]. In 2013, the State Council promulgated the "National Sustainable Development Plan for Resource-based Cities (2013-2020)," which identified 262 resource-based cities in China and divided them into four types: growth, mature, decline, and regeneration [45]. (3) Sponge city: the construction of sponge city is considered as an inevitable requirement of the new urbanization road in China and also 
an important task to be strengthened and gradually implemented in the process of urban construction [46]. Under the background of the implementation of a series of macropolicies, for instance, "Technical Guidelines for Sponge City Construction" and "Guiding Opinions on Promoting Sponge City Construction," China has identified about 16 pilot sponge cities which can minimize the impact of urban development and construction on the ecological environment by taking comprehensive measures such as "infiltration, stagnation, storage, purification, utilization, and discharge." (4) Zero-waste city: the State Council issued the "Working Plan for the Pilot Project of Zero-waste city" in January 2019, which pointed out that it is necessary to strengthen the guidance of top-level design, establish the construction indicator system of "zero-waste city," implement green industrial production, promote green agricultural production, practice green lifestyle, enhance the ability of risk prevention and control, and stimulate the vitality of market players [47]. Till now, China has established 11 cities, including Shenzhen in Guangdong Province, Tongling in Anhui Province, and Sanya in Hainan Province, as pilot cities for the construction of "zero-waste cities" and at the same time, Hebei Xiongan New Area and Beijing Economic and Technological Development Zone as exceptional cases to promote together [48]. (5) Eco-city program: a series of macromanagement policy orientations of the State Environmental Protection Administration and the Ministry of Construction have been formulated (such as "Notice on Naming Garden City," "Implementation Measures for Quantitative Assessment of Urban Environmental Comprehensive Improvement," "Planning for the Construction of National Ecological Demonstration Zones (1996-2050)," and "Notice on Issuing the Implementation Opinions on Creating an Ecological Garden City"), triggering a wave of urban ecological environment construction in China. Under the promotion of a series of policies, the construction of environmental cities in China has made significant progress. Since Yichun city of Jiangxi Province put forward the plan and construction of ecological demonstration city in 1988, Beijing, Shanghai, and other cities have begun to explore the construction road of "green city" and "eco-city" [49].

4.2. Local Level. During the development of the urban circular economy, a series of policies have been formulated at the local level. For example, as one of the earliest provinces and cities to carry out the research and practice of circular economy in China, in 2005, Shanghai municipal government organized and compiled the "Shanghai Circular Economy White Paper," which established the strategic thinking and main goals for the development of circular economy in 2010 and 2020. To strengthen the management of urban domestic waste and improve the living environment, Shanghai has formulated the "Regulations of Shanghai Municipality on the Management of Domestic Waste," which is a kind of complete regulation for the recycling and utilization of urban waste [50]. For Beijing, in the process of building an eco-city, various regions in Beijing have launched explorations. For instance, Changping District has made every effort to build modern agriculture and brought the ecological red line into the scope of ecological civilization system reform; Tongzhou District is actively creating the ecological characteristics of the city's subcenter. In promoting the construction of zero-waste cities, Beijing Economic and Technological Development Zone is the first batch of pilot cities in China. Beijing has promulgated the "Regulations on the Management of Domestic Waste in Beijing," which is the first local regulation on the recycling and utilization of urban waste. It has detailed regulations on the links from the beginning of the collection to the final recycling of urban domestic waste. In addition, Beijing has issued the "Regulations on the Prevention and Control of Air Pollution in Beijing," which mainly explained the contents of joint prevention and control, total emission control of critical pollutants, pollution prevention and control of fixed sources of pollution, pollution prevention and control of motor vehicles and nonroad mobile machinery, dust pollution prevention and control, legal liability, and other contents [51]. Jiangsu Province released the "Jiangsu Province Low-Carbon Development Report (2019)" in 2020, which introduces the construction of low-carbon cities and zerowaste cities in Jiangsu Province [52]. Nanjing promoted the legislative work of the "Nanjing City Low-Carbon Development Promotion Regulations," actively constructed a mechanism for the participation of the whole people, and carried out the activity of "low-carbon travel for all people." Xuzhou comprehensively promoted the pilot project of "zero-waste city" construction and formulated the Implementation Plan of "Zero-Waste City" construction pilot project of Xuzhou Ecological Environment Bureau. Zhenjiang City successfully held the 4th International Low-Carbon (Zhenjiang) Conference and formulated the "2019 Zhenjiang City Low-Carbon City Construction Assessment Rules.”

\section{Indicators for Measuring Urban-Scale Circular Economy}

The statistical analysis technology of urban circular economy can comprehensively analyze the material flow, energy flow, value flow, currency flow, population flow, and information flow in the urban system. Through visual expression and analysis of the development status, development efficiency, and development trend of the urban circular economy, it can provide path guidance for the sustainable development of cities. On the one hand, by combing the evaluation indicators of urban-scale circular economy development, analyzing the principles, starting points, objectives, advantages, and disadvantages of index design, and discussing the index system and changes in the policy system, we hope to put forward the index system of urban-scale circular economy research in the future. On the other hand, this paper analyzes the advantages and disadvantages of urban-scale circular economy research methods and their application practice, hoping to provide guidance for future research.

5.1. Construction of Urban-Scale Circular Economy Indicator System. In order to evaluate and guide the construction and development of urban circular economy reasonably, it is necessary to establish a set of guiding and comprehensive 
indicator system of the circular economy to guide the operation and operation of circular economy [53]. In the process of exploring the indicator system of the urban-scale circular economy, domestic scholars have explored from different aspects. For example, $\mathrm{Yu}$ and Feng proposed a 24indicator system which includes economic development indicator, green development indicator, and human development indicator, based on the four significant systems of industry, urban infrastructure, human settlement environment, and social consumption, in order to evaluate the total development amount and efficiency of the development of urban circular economy [54]. However, it seems that all the indices are less involved in urban garbage, water resources, and other indicators, which is challenging to meet the current national "sponge city" and "zero-waste city" construction evaluation requirements. Based on the " $3 \mathrm{R}$ principle," Zhang and Huang constructed an indicator system from five aspects: resource reduction input, resource recycling, pollutant emission reduction, ecological environment quality, and economic and social development to evaluate the comprehensive level of urban circular economy development [55]. For resource-based cities, Li and Zhang constructed an indicator system from four aspects of resources, economy, ecological environment, and society to evaluate the development level of the circular economy in resource-based cities [56]. However, their research did not analyze the correlation of the indicators, which would result in more uncertainty. Generally, Chinese scholars mostly build the indicator system around economic development, social development, resource utilization, environmental quality, pollution reduction, and other aspects based on the "3R principle." The relevant research is also relatively mature. However, in the specific practice process, there are still some problems in the indicator system, such as no unified standard, too many and various indicators, and too much emphasis on universality.

Along with the development process, both national and local governments have successively launched the policy systems of eco-city, urban mineral, sponge city, and zerowaste city. With the change of policy system, Chinese scholars put forward a series of specific and targeted indicator systems [57-59] (Table 1). For example, the indicator evaluation system of eco-city can be constructed from the aspects of system guarantee, ecological settlement, environmental support, economic operation, consciousness, and culture. However, there are differences in the evaluation focus of different policy systems; for instance, eco-city emphasizes the exploration of ecological environment, urban mineral emphasizes the management and control of substantial resources, the sustainable development of resource-based cities emphasizes the measurement of resources and development transformation, sponge city emphasizes the measurement of water resources, and zerowaste city emphasizes the monitoring of solid waste. At this stage, China mainly advocates the construction of the zerowaste city, and scholars' research themes are mostly focused on garbage recycling. Faced with this situation, we can design the indicator system of the urban-scale circular economy according to the " $3 \mathrm{R}$ principle," from the aspects of resource reduction input, resource recycling, pollutant emission reduction, ecological environment quality, economic and social development, policy system, and so on. At the specific indicator level, we can focus on the measurement of waste industrialization rate, waste recycling rate, waste classification treatment rate, and waste recovery and comprehensive utilization rate. In this way, we can not only evaluate the development of urban-scale circular economy but also evaluate the government performance.

\subsection{Discussion on Research Methods of Urban-Scale Circular} Economy. In the study of the urban circular economy, Chinese scholars mainly use material flow analysis, emerge analysis, ecological footprint, ecological efficiency, system dynamics, and other methods. The advantages and disadvantages of each technique and its application practice are shown in Table 2. In the process of use, material flow analysis can provide sustainability indicators for the development of urban circular economy [60]. Emerge analysis can directly reflect the overall situation of urban circular economy development [61]. An ecological footprint can help to judge whether the development of an urban is sustainable [62]. Ecological efficiency can directly reflect the level of circular economy development [63]. System dynamics analysis can reflect the dynamic urban changes of the municipal circular economy [64]. However, there are some shortcomings in these methods; for example, material flow analysis lacks the research of value flow, water resources, and land resources; ecological footprint lacks the study of value flow, and the indicators are few, which cannot carry more information; emerge analysis needs more indicators; the calculation method and indicator system of ecological efficiency need to be strengthened; the variable design needs to be supported in system dynamics, data mining, etc. This makes the scholars use a variety of methods in the process of use; for example, some scholars combined material flow analysis and ecological footprint to construct the sustainable development evaluation indicator system of resource-based cities [65]. In addition, in the process of urban circular economy research, scholars also use life cycle assessment, data envelopment analysis, fuzzy comprehensive evaluation, principal component analysis, neural network, gray correlation analysis, and other methods. With the help of a variety of research methods, we can build a perfect indicator system of urban circular economy development and virtually explore the development level, development efficiency, and evolution trend of the urban circular economy, and the extensive use of these methods can also make the research on the urban circular economy more mature.

\section{Discussion and Conclusion}

At present, the research of urban circular economy in China has entered a new stage of development. Chinese scholars mostly explore the microlevel material flow of elements and materials from the perspective of circulation, which puts forward higher requirements for the depth and breadth of scholars' professional knowledge. The research themes of 
TABLE 1: Design of the indicator system in different policy practices.

\begin{tabular}{|c|c|c|}
\hline Perspective & Indicator system & Critical points of indicator system \\
\hline Eco-city & $\begin{array}{c}\text { System guarantee, ecological settlement, environmental support, economic } \\
\text { operation, consciousness, and culture }\end{array}$ & Ecological environment \\
\hline Urban mineral & $\begin{array}{c}\text { Development potential of urban mineral, utilization rate of waste resources, } \\
\text { waste discharge, ecological environment, "urban mineral" development } \\
\text { concept, economic development, social development, technological innovation, } \\
\text { and government support }\end{array}$ & Control of old resources \\
\hline $\begin{array}{l}\text { Resource-based } \\
\text { city }\end{array}$ & $\begin{array}{c}\text { Economic development, people's livelihood improvement, resource guarantee, } \\
\text { and ecological environment protection }\end{array}$ & $\begin{array}{l}\text { Resource situation, urban } \\
\text { development, and transformation }\end{array}$ \\
\hline Sponge city & $\begin{array}{l}\text { Water ecology, water environment, water resources, water security, system } \\
\text { construction and implementation, and display of water resources }\end{array}$ & Water resources \\
\hline Zero-waste city & $\begin{array}{l}\text { Solid waste, specifically from the source of solid waste reduction, solid waste } \\
\text { resource utilization, solid waste final disposal, security capacity, and public sense } \\
\text { of gain }\end{array}$ & Solid waste \\
\hline
\end{tabular}

TABLe 2: Methods and the application.

\begin{tabular}{|c|c|c|c|c|}
\hline Method & Advantages & Weakness & Referring city & Application \\
\hline $\begin{array}{l}\text { Material flow } \\
\text { analysis }\end{array}$ & $\begin{array}{c}\text { Grasp the material flow } \\
\text { situation and promote energy } \\
\text { conservation and emission } \\
\text { reduction }\end{array}$ & $\begin{array}{l}\text { Uncertainty in hidden flow } \\
\text { accounting and few analyses of } \\
\text { water and land }\end{array}$ & $\begin{array}{l}\text { Guiyang } \\
\text { Jiangsu } \\
\text { Province } \\
\text { Xuzhou } \\
\text { Xi'an }\end{array}$ & $\begin{array}{l}\text { Describe the characteristics of urban } \\
\text { circular economy } \\
\text { Construction of ecological efficiency } \\
\text { evaluation indicator system } \\
\text { Analysis of sustainable state } \\
\text { Evaluation of the development of } \\
\text { circular economy }\end{array}$ \\
\hline $\begin{array}{l}\text { Emergy } \\
\text { analysis }\end{array}$ & $\begin{array}{l}\text { Transform the elements of } \\
\text { ecosystem and economic } \\
\text { system into the same indicator } \\
\text { of magnitude }\end{array}$ & $\begin{array}{c}\text { Some limitations in the } \\
\text { evaluation of human factors } \\
\text { including system, culture, and } \\
\text { politics }\end{array}$ & $\begin{array}{l}\text { Qaidam Basin } \\
\text { Yulin } \\
\text { Shizuishan }\end{array}$ & $\begin{array}{l}\text { Analysis of the development of urban } \\
\text { circular economy } \\
\text { Construction of emergy evaluation } \\
\text { indicator system }\end{array}$ \\
\hline $\begin{array}{l}\text { Ecological } \\
\text { footprint }\end{array}$ & $\begin{array}{c}\text { Make clear the sustainable } \\
\text { status of the economy in terms } \\
\text { of ecology }\end{array}$ & $\begin{array}{l}\text { Lack of research on value flow, get } \\
\text { conceptual data, and have poor } \\
\text { operability; less information with } \\
\text { fewer indicators }\end{array}$ & $\begin{array}{l}\text { Guangzhou } \\
\text { Wuhan } \\
\text { Yichun } \\
\text { Daqing }\end{array}$ & $\begin{array}{l}\text { Analyzes the dynamic change process } \\
\text { of urban ecological footprint } \\
\text { Evolution characteristics of ecological } \\
\text { environment and ecological pressure } \\
\text { Provides the idea and realization path } \\
\text { and method of urban transformation } \\
\text { Spatial and temporal changes of urban } \\
\text { ecological carrying capacity }\end{array}$ \\
\hline $\begin{array}{l}\text { Ecological } \\
\text { efficiency }\end{array}$ & $\begin{array}{l}\text { Emphasize the combination of } \\
\text { economy and environment }\end{array}$ & $\begin{array}{l}\text { Calculation methods and } \\
\text { indicator system need to be } \\
\text { strengthened }\end{array}$ & $\begin{array}{c}16 \text { resource- } \\
\text { based cities } \\
\text { Liaoning } \\
\text { Province } \\
\text { Jiangxi } \\
\text { Province } \\
\text { Shizuishan }\end{array}$ & $\begin{array}{l}\text { Understand the development of } \\
\text { circular economy in resource-based } \\
\text { cities } \\
\text { Comprehensive measurement of } \\
\text { circular economy development } \\
\text { Analysis of the changing track of the } \\
\text { development mode of urban circular } \\
\text { economy } \\
\text { Analysis on the development level of } \\
\text { industrial circular economy }\end{array}$ \\
\hline $\begin{array}{l}\text { System } \\
\text { dynamics }\end{array}$ & $\begin{array}{l}\text { Low requirement for data } \\
\text { accuracy; complex practical } \\
\text { problems handling }\end{array}$ & $\begin{array}{l}\text { Obstacles to variable design and } \\
\text { data mining }\end{array}$ & $\begin{array}{l}\text { Lanzhou } \\
\text { Qinghai } \\
\text { Province }\end{array}$ & $\begin{array}{l}\text { Analyzes the main cause and effect } \\
\text { feedback relationship of urban circular } \\
\text { economy system } \\
\text { Shows the feedback relationship } \\
\text { between economic growth, resource } \\
\text { depletion, and environmental impact } \\
\text { Simulates the dynamic change process } \\
\text { of the urban complex system under the } \\
\text { mode of the circular economy under } \\
\text { long time series } \\
\text { Analysis of the changing law and trend } \\
\text { of critical water resources parameters }\end{array}$ \\
\hline
\end{tabular}


scholars mostly focus on waste recycling, which requires scholars to introduce new technologies and new ideas to explore reduction, classification and recycling, waste management, resource utilization, and so on [66]. With the deepening of the research, the relevant indicator system may become more and more complex and specific, which requires scholars to have the idea of integration, and be able to construct the indicator system from multiple angles, large scope, and deep level [67]. At the same time, with the continuous increase of research fields and research data, it may be necessary to integrate multidisciplinary methods such as computer science and geography. For example, some scholars use ant colony optimization algorithm to explore the intelligent growth boundary of Changsha-ZhuzhouXiangtan Urban Agglomeration [68]. For the future research direction of the urban circular economy, scholars put forward different views. Grey and Tarascon pointed out that future research may be multidisciplinary. For example, in order to introduce new technologies into the market and social needs, an original analysis method is needed [69]. Geissdoerfer believes that the relationship between the circular economy and new concepts, such as sharing economy, may be explored in the future [70]. Some scholars believe that future research on the urban circular economy may pay more attention to SME level $[71,72]$. Based on the above research results, we propose that the future research focus of urban-scale circular economy is as follows:

(1) New method in new data contexts such as integrating big data and technologies based on GIS technology, system dynamics model, and artificial neural network should be developed. In order to carry out the development evaluation of the urban circular economy, we need to focus on the international development situation, highlight the region characteristics, and construct the evaluation indicator system and method of circular economy suitable for different regions' natural, social, economic, and technological development levels. There are dynamic spatial expression and simulation, as well as time series prediction and analysis. By constructing an artificial neural network model, we can simulate the relationship of influencing factors of the urban cycle and provide technical support for the construction and evaluation of urban circular economy indicator systems. In addition, the integration of various mathematical models and GIS is also a useful research method at present [73].

(2) A systemic roadmap by integrating "governmentled, market-driven, legal norms, policy support, technological support, and public participation" is proposed. By optimizing the macro-control tool led by the government, making full use of administrative, legal, economic, and financial means, the circular economy is standardized to ensure the sustainable development of the social economy; the incentive mechanism for the development of the circular economy is constructed to guide and encourage enterprises and consumers to implement the development strategy of the circular economy and to promote the development of the circular economy by using price leverage. We should take effective mechanisms to connect all kinds of subjects closely and rely on the cooperation and joint action of different participants. Integrating the interests of enterprises as the core subject, as well as auxiliary governance subjects such as consumers, government, universities, scientific research institutions, financial institutions, intermediary organizations, and news media, aiming at different fields such as land, energy, water, and important raw materials, the resource integration and optimal allocation among different subjects can be realized through reasonable process design and institutional arrangement [74].

(3) New concepts such as "Internet +," "sharing economy," "Internet of Things," and "artificial intelligence" should be taken into account seriously for circular economy development. In the process of developing a circular economy in cities, the resource recycling network constructed by the Internet of Things, cloud computing, big data, and other technologies can not only effectively collect the relevant information of resource recovery and processing, but also realize the whole process link of source recovery, process control, and terminal processing and the sharing of information and resources. Through data sharing, government departments and industry regulators can monitor the whole process of resource recycling in real time. In view of the problems existing in the resource recovery and treatment, relevant policies and regulations are issued in time, so as to comprehensively improve the supervision and management level of the resource recovery and utilization industry and make the resource recycling industry develop in a healthy and orderly direction [75]. The sharing economy only occurs in the field of consumption. The reuse of idle resources does not need production costs, only transaction costs, and there are no production loss and environmental pollution. It is the most economical and environmentally friendly recycling mode, the advanced stage of the development of the circular economy, and the most ideal ecological economy. The sharing economy can be regarded as a subcycle of circular economy, which is called "produce product, consume, re-consume, reproduce product." The combination of sharing economy and circular economy can maximize the utilization of resources, which is a sustainable green development mode [76].

\section{Conflicts of Interest}

The authors declare that they have no conflicts of interest.

\section{Acknowledgments}

This work was supported by the Key Program of "Thousand People Plan" of Jiangxi Province and Shaanxi Province, the Social Science Foundation of China (Grant ID: 17XJY018), 
Natural Science Foundation of China (Grant ID: 41971166), and MOE Project of Humanities and Social Sciences of China (Grant ID: 19YJAZH076).

\section{References}

[1] J. L. Ruiz-Real, J. Uribe-Toril, J. D. P. Valenciano, and J. C. Gázquez-Abad, "Worldwide research on circular economy and environment: a bibliometric analysis," International Journal of Environmental Research and Public Health, vol. 15, no. 12, p. 2699, 2018.

[2] F. Blomsma and G. Brennan, "The emergence of circular economy: a new framing around prolonging resource productivity," Journal of Industrial Ecology, vol. 21, no. 12, pp. 603-614, 2017.

[3] J. Yang, S. Jin, X. Xiao et al., "Local climate zone ventilation and urban land surface temperatures: towards a performancebased and wind-sensitive planning proposal in megacities," Sustainable Cities and Society, vol. 47, pp. 1-11, 2019.

[4] B. Xue, X.-p. Chen, Y. Geng et al., "Survey of officials' awareness on circular economy development in China: based on municipal and county level," Resources, Conservation and Recycling, vol. 54, no. 12, pp. 1296-1302, 2010.

[5] Y. Kalmykova, M. Sadagopan, and L. Rosado, "Circular economy-from review of theories and practices to development of implementation tools," Resources, Conservation and Recycling, vol. 135, pp. 190-201, 2018.

[6] Y. Geng, J. Sarkis, and R. Bleischwitz, "How to globalize the circular economy," Nature, vol. 565, no. 7738, pp. 153-155, 2019.

[7] F. Bassi and J. G. Dias, "Sustainable development of small-and medium-sized enterprises in the European Union: a taxonomy of circular economy practices," Business Strategy and the Environment, vol. 29, no. 6, pp. 2528-2541, 2020.

[8] B. Xue, "Resource and environmental management and the circular economy," in Resource and Environmental Management, B. Mitchell, Ed., Oxford University Press, New York, NY, USA, 3rd edition, 2019.

[9] Y. Geng, J. Fu, J. Sarkis, and B. Xue, “Towards a national circular economy indicator system in China: an evaluation and critical analysis," Journal of Cleaner Production, vol. 23, no. 1, pp. 216-224, 2012.

[10] W. R. Stahel, "The circular economy," Nature, vol. 531, no. 7595, pp. 435-438, 2016.

[11] Y. Geng, J. Sarkis, S. Ulgiati, and P. Zhang, "Measuring China's circular economy," Science, vol. 339, no. 6127, pp. 1526-1527, 2013.

[12] N. Gregson, M. Crang, S. Fuller, and H. Holmes, "Interrogating the circular economy: the moral economy of resource recovery in the EU," Economy and Society, vol. 44, no. 2, pp. 218-243, 2015.

[13] D. Lazarevic and H. Valve, "Narrating expectations for the circular economy: towards a common and contested European transition," Energy Research \& Social Science, vol. 31, no. 1, pp. 60-69, 2017.

[14] G. Moraga, S. Huysveld, F. Mathieux et al., "Circular economy indicators: what do they measure?," Resources, Conservation and Recycling, vol. 146, pp. 452-461, 2019.

[15] P. Ghisellini, C. Cialani, and S. Ulgiati, "A review on circular economy: the expected transition to a balanced interplay of environmental and economic systems," Journal of Cleaner Production, vol. 114, pp. 11-32, 2016.

[16] B. Xue, X. Xiao, and J. Li, "Identification method and empirical study of urban industrial spatial relationship based on
POI big data: a case of Shenyang city, China," Geography and Sustainability, vol. 1, no. 2, pp. 152-162, 2020.

[17] H. Leng and S. Y. Song, "International experience and enlightenment of urban-scale building energy conservation planning," Urban Planning International, vol. 35, no. 3, pp. 103-112, 2020.

[18] M. D. Zhang, "Study on spatial difference of urban circular economy development efficiency," Journal of China University of Geosciences (Social Science Edition), vol. 16, no. 3, pp. 95104, 2016.

[19] M. Åkerman, N. Humalisto, and S. Pitzen, "Material politics in the circular economy: the complicated journey from manure surplus to resource," Geoforum, vol. 116, pp. 73-80, 2020.

[20] Z. P. Yang, J. Sun, and Y. S. Xu, "Cleaner production and circular economy," Chemical Environmental Protection, vol. 2, pp. 160-164, 2005.

[21] D. M. Chen, B. L. Li, and Y. L. Chen, "Analysis of enterprise behavior in circular economy development mode," Economic Issues, vol. 9, pp. 34-36, 2003.

[22] Z. J. Wu, "Research on the development of eco industrial parks in China," Contemporary Finance and Economics, vol. 11, pp. 66-72, 2007.

[23] Z. Wang, L. Y. Miao, and Q. Ma, "Research and application of cleaner production evaluation indicator system for coal mining enterprises," Coal Field Geology and Exploration, vol. 4, pp. 45-48, 2006.

[24] Z. Shi, X. Hou, and J. Bao, "Study on the policy mechanism of cleaner production in China," Environmental Protection, vol. 2, pp. 12-14+28, 2004.

[25] D. Liu, Z. Wang, and C. Song, "Lubei eco industrial park: a specimen of circular economy practice," Outlook Newsweek, vol. 49, pp. 58-59, 2005.

[26] J. Feng, J. Yin, and L. Chu, "Circular economy theory and its practice in China," Chinese Population, Resources and Environment, vol. 2, pp. 31-36, 2003.

[27] Y. Ren, Y. Chen, G. Zhou et al., "Development model of circular economy in China," Chinese Population, Resources and Environment, vol. 5, pp. 141-146, 2005.

[28] Y. Zhou and C. Zhang, "A review on the research and practice of "urban mineral" at home and abroad," Academic Forum, vol. 35, no. 4, pp. 118-124, 2012.

[29] C. Wang, J. Xu, and H. Yao, "Review of urban mineral theory research," Resource Science, vol. 36, no. 8, pp. 1618-1625, 2014.

[30] Y. Zhang, F. Lin, and W. Jiang, "Problems and countermeasures in the construction of community circular economy: a case study of Minhang district, Shanghai," Environmental Science and Technology, vol. 10, pp. 154-157, 2008.

[31] L. Fu, X. Chen, and Z. Leng, "Study on ecological efficiency of Urban agglomeration based on super efficiency DEA model: a case study of Changsha Zhuzhou Xiangtan " $3+5$ ” urban agglomeration," China Population, Resources and Environment, vol. 23, no. 4, pp. 169-175, 2013.

[32] P. Wang, "Connotation of "two oriented society" and sustainable development of regional economy: a case study of Wuhan city circle," Journal of Jilin Institute of Technology and Technology, vol. 5, pp. 72-76, 2008.

[33] M. Dong and B. Zou, "Empirical study on evaluation and countermeasures of urban two oriented society development," Regional Research and Development, vol. 31, no. 3, pp. 126130, 2012. 
[34] G. He, Y. Zhao, J. Wang et al., "The effects of urban water cycle on energy consumption in Beijing, China," Journal of Geographical Sciences, vol. 29, no. 6, pp. 959-970, 2019.

[35] W. Sun, W. Chen, and Z. Jin, "Spatial function regionalization based on an ecological-economic analysis in Wuxi city, China," Chinese Geographical Science, vol. 29, no. 2, pp. 352-362, 2019.

[36] L. Zhang, Z. Niu, Q. Zhang et al., "Analysis of the top-level design of sponge city construction," Water Supply and Drainage, vol. 53, no. 9, pp. 1-5, 2017.

[37] Y. Peng, L. Li, X. Peng et al., "Development process of domestic waste classification in China? Obstacles and countermeasures," China Environmental Science, vol. 38, no. 10, pp. 3874-3879, 2018.

[38] F. Zhong, Q. Su, R. Zhou et al., "Simulation analysis of the impact of straw burning on regional urban air quality," Climate and Environment Research, vol. 22, no. 2, pp. 149-161, 2017.

[39] Y. Chen, J. Teng, N. Zhao et al., "Connotation, goal and construction path of "zero-waste city" pilot construction," Environmental Protection, vol. 47, no. 9, pp. 21-25, 2019.

[40] X. Ma, "Analysis of the development strategy of fresh agricultural products cold chain logistics in the background of 'Internet plus'," Business Economics Research, vol. 6, pp. 212-214, 2017.

[41] National Development and Reform Commission, Ministry of Finance, "Notice on carrying out the construction of urban minerals demonstration bases," 2014, http:// fgfybfae5ff103a44b2980073f5c968c57a4h09v99qf56fwo6wc0. fffg.wap.gxlib.org/upload/xxnr/1002320122287780.pdf.

[42] P. H. Brunner, "Urban mining a contribution to reindustrializing the city," Journal of Industrial Ecology, vol. 15, no. 3, pp. 339-341, 2011.

[43] P. T. Jones, D. Geysen, Y. Tielemans et al., "Enhanced landfill mining in view of multiple resource recovery: a critical review," Journal of Cleaner Production, vol. 55, pp. 45-55, 2013.

[44] J. Yu, J. Li, and W. Zhang, "Identification and classification of resource-based cities in China," Journal of Geographical Sciences, vol. 29, no. 8, pp. 1300-1314, 2019.

[45] MEE (Ministry of Ecological Environment of China), "National sustainable development plan for resource-based city (2013-2020)," 2013, http://www.mee.gov.cn/zcwj/gwy wj/ 201811/t20181129_676558.shtml?keywords=\%E5\%9F\%8E\% E5\%B8\%82.

[46] Y. Wang, "Discussion on the construction of sponge city control indicator system," Planner, vol. 32, no. 5, pp. 10-16, 2016.

[47] MEE (Ministry of Ecological Environment of China), "Notice of the general office of the State Council on printing and distributing the pilot work plan of zero-waste city," 2019, http://www.mee.gov.cn/zcwj/gwywj/201901/t20190123_ 690456.shtml?keywords=\%E5\%9F\%8E\%E5\%B8\%82.

[48] MEE (Ministry of Ecological Environment of China), "Announcement on issuing the list of pilot projects of zero-waste city," 2019, http://www.mee.gov.cn/xxgk2018/xxgk/xxgk 01/ 201905/t20190505_701858.html?Keywords =\%E5\%9F\%8E\% $\mathrm{E} 5 \% \mathrm{~B} 8 \% 82$.

[49] Y. Jiang, C. Liu, C. Zhou et al., "The oretical research status and practical problems of ecological city in China," Geographic Research, vol. 34, no. 12, pp. 2222-2237, 2015.

[50] Shanghai Municipal Government, "Regulations of Shanghai municipality on the management of domestic waste," 2019, https://sthj.sh.gov.cn/hbzhywpt1013/hbzhywpt1019/20 200629/c014eeb63cd34fa3b90dfd88478bb67c.html.
[51] Beijing Municipal Government, "Regulations of Beijing municipality on the prevention and control of air pollution," 2018, http://sthjj.beijing.gov.cn/bjhrb/indicator/xxgk 69/ zfxxgk43/fdzdgknr2/flfg77/17446 40/indicator.html.

[52] Jiangsu Provincial Government, "Low carbon development report of Jiangsu province," 2019, http://hbt.jiangsu.gov.cn/ art/2020/7/7/art_74113_9294398.html.

[53] H. Xu and M. G. Wang, "Evaluation of urban circular economy development based on combination weight grey correlation analysis," Science and Technology and Engineering, vol. 12, no. 10, pp. 2499-2504, 2012.

[54] L. Y. Yu and Z. J. Feng, "Design of evaluation indicator system of urban circular economy," China Soft Science, vol. 12, pp. 44-53, 2005.

[55] B. Zhang and X. J. Huang, "Research and empirical evaluation of circular economy development indicator system," China Population, Resources and Environment, vol. 3, pp. 22-25, 2005.

[56] W. F. Li and T. Z. Zhang, "Study on evaluation indicator system of circular economy in resource-based cities," Science of Science and Management of Science and Technology, vol. 8, pp. 82-85, 2005.

[57] W. S. Qin, Y. F. Zhang, and J. Yuan, "Measuring and defining eco-civilization cities in China," Resources Science, vol. 35, no. 8, pp. 1677-1684, 2013.

[58] L. J. Guo and Y. S. Zhou, "Innovation of development path of urban mineral resources based on the perspective of development level," Huxiang Forum, vol. 30, no. 3, pp. 92-97, 2017.

[59] Q. Zou and X. H. Wang, "Waste free index: quantitative evaluation method of construction effect of waste free city," Environmental Protection, vol. 48, no. 8, pp. 46-50, 2020.

[60] H. P. Huang, J. Bi, B. Zhang et al., "Review of material flow analysis," Acta Ecologica Sinica, vol. 1, pp. 368-379, 2007.

[61] X. P. Chen and B. Xue, "Research on circular economy in Northwest China based on emergy analysis," Resource Science, vol. 1, pp. 52-59, 2005.

[62] J. H. Zhang and J. Zhang, "Research progress and enlightenment of ecological footprint model in China," Regional Research and Development, vol. 2, pp. 90-96, 2007.

[63] Y. Ren, C. Fang, X. Lin, S. Sun, G. Li, and B. Fan, "Evaluation of the eco-efficiency of four major urban agglomerations in coastal eastern China," Journal of Geographical Sciences, vol. 29, no. 8, pp. 1315-1330, 2019.

[64] Z. H. Chen, "Research on water resources circular economy in Tieling city based on SD model," Water Conservancy Planning and Design, vol. 5, pp. 83-86+142, 2018.

[65] H. H. Zhao, Y. Wang, X. M. Gu et al., "Establishment of environmental sustainability assessment indicators based on material flow and ecological footprint model in Tongling city of Anhui province," Acta Ecologica Sinica, vol. 32, no. 7, pp. 2025-2032, 2012.

[66] D. L. M. Nascimento, V. Alencastro, O. L. G. Quelhas et al., "Exploring industry 4.0 technologies to enable circular economy practices in a manufacturing context: a business model proposal," Journal of Manufacturing Technology Management, vol. 30, no. 3, 2019.

[67] K. Govindan and R. Sivakumar, "Green supplier selection and order allocation in a low-carbon paper industry: integrated multi-criteria heterogeneous decision-making and multiobjective linear programming approaches," Annals of Operations Research, vol. 238, pp. 1-2, 2016.

[68] S. Ma, Y. Zhao, and X. Tan, "Exploring smart growth Boundaries of urban agglomeration with land use spatial optimization: a case study of Changsha-Zhuzhou-Xiangtan 
city group, China," Chinese Geographical Science, vol. 30, no. 4 , pp. $665-676,2020$.

[69] C. P. Grey and J. M. Tarascon, "Sustainability and in situ monitoring in battery development," Nature Materials, vol. 16, no. 1, pp. 45-56, 2016.

[70] M. Geissdoerfer, P. Savaget, N. M. P. Bocken, and E. J. Hultink, "The Circular economy-a new sustainability paradigm?," Journal of Cleaner Production, vol. 143, pp. 757-768, 2017.

[71] C. Vallaster, S. Kraus, N. Kailer, and B. Baldwin, "Responsible entrepreneurship: outlining the contingencies," International Journal of Entrepreneurial Behavior \& Research, vol. 25, no. 3, pp. 538-553, 2019.

[72] S. Kraus, J. Burtscher, C. Vallaster et al., "Sustainable entrepreneurship orientation: a reflection on Status-Quo research on factors facilitating responsible managerial practices," Sustainability, vol. 10, p. 144, 2018.

[73] X. M. Shao, Q. Liu, and Y. Y. Zhang, "Research progress and Prospect of land intensive use," Progress in Geographical Sciences, vol. 2, pp. 85-95, 2006.

[74] Q. C. Zhang, "Research on municipal solid waste treatment mechanism: an analytical framework for collaborative governance," Journal of Jiangnan University (Humanities and Social Sciences), vol. 18, no. 3, pp. 83-91, 2019.

[75] Y. X. Li and W. Y. Chen, "Research on the construction of recycling system of renewable resources under the Internet plus background," Western Accounting, vol. 1, pp. 74-77, 2020.

[76] C. H. Dong, "Sharing economy: theory and reality," Journal of Guangdong University of Finance and Economics, vol. 31, pp. 4-15, 2016. 